\title{
On the Phonological Derivation of Compensatory Lengthening in Standard Malay: A Stratal Optimality Theoretical Approach
}

\author{
Mufleh Salem M. Alqahtani \\ Linguistics and Translation Studies Dept. College of Languages and Translation, King Saud \\ University, KSA. \\ mqahtani1@ksu.edu.sa
}

DOI: http://doi.org/ 10.36892/ijlls.v4i1.804

\begin{tabular}{|c|c|}
\hline $\begin{array}{l}\text { Received: } \\
\text { 01/01/2022 }\end{array}$ & $\begin{array}{c}\text { Abstract } \\
\text { This study used Stratal Optimality Theory (OT) as the analytical framework }\end{array}$ \\
\hline $\begin{array}{l}\text { Accepted: } \\
\text { 29/01/2022 }\end{array}$ & $\begin{array}{l}\text { to analyze the phonological derivation of Compensatory Lengthening (CL) in } \\
\text { Standard Malay that targets the moraic rhotic } / r / \text { in the coda position. It was } \\
\text { concluded that to ensure the moraicity assignment to the rhotic } / r / \text { in the } \\
\text { postvocalic position before any consonant deletion or vowel lengthening, the }\end{array}$ \\
\hline $\begin{array}{l}\text { Keywords: } \\
\text { Standard Malay; } \\
\text { Compensatory } \\
\text { Lengthening; Weight- } \\
\text { by-Position; } \\
\text { counterbleeding; } \\
\text { Stratal OT. }\end{array}$ & $\begin{array}{l}\text { moraic structures were built based on Weight-By-Position (WBP) prior to the } \\
\text { segmental changes that resulted in the CL, which meant that the floating } \\
\text { mora became affiliated to the preceding stem vowel. This phonological } \\
\text { derivation was seen to be a form of counterbleeding in which the consonant } \\
\text { deletion counterbleeds the WBP. The Stratal OT model successfully accounts } \\
\text { for this counterbleeding as an opaque rule interaction, with the first stratum } \\
\text { ensuring that the moraic structure is built before any segmental deletion or } \\
\text { lengthening changes and the second stratum dealing with the CL. }\end{array}$ \\
\hline
\end{tabular}

\section{INTRODUCTION}

Segmental changes in Malay have attracted continual linguistic research attention (Asmah 1975; Yunus 1980; Onn 1980; Collins \& Hassan 1986; Zaharani 1991, 2005; Teoh 1994; Kassin 2000; Zaharani \& Jalaluddin 2011), the first of whom was Asmah (1975), who pioneered Malay phonological analysis and along with Yunus (1980) and Onn (1980) recognized the initial stage vowel lengthening in Malay when the stem-final $/ \mathrm{r} /$ was not being pronounced. For example, Yunus (1980) found that the same segment is dropped by a vast majority of Malay speakers in Singapore and is used interchangeably without semantic impact; for example, [bəna] or [bənar] 'true or correct'. Onn (1980: 47) gave the following examples for the deletion of the stem-final /r/ in Malay:

(1) r-Deletion in Onn (1980: 47):

\begin{tabular}{llll}
\hline a. & /bakar/ & [baka] & 'burn' \\
\hline b. & /tukar/ & {$[$ tuka $]$} & 'change' \\
c. & /kisar/ & {$[$ kisa $]$} & 'revolve' \\
d. & /hindar/ & [hinda $]$ & 'avoid'
\end{tabular}

Collins \& Hassan (1986) and Zaharani (1991) built on this early analysis of the stemfinal $/ \mathrm{r}$, finding that the stem-final $/ \mathrm{r} /$ deletion was accompanied by a lengthening of the preceding vowel, a process commonly observed in many Malay dialects known as compensatory lengthening (CL). In keeping with Collins \& Hassan and Zaharani's depictions of CL in Standard Malay as involving the relinking of the timing X-slot to the preceding vowel, 
Teoh (1994) proposes delinking first be represented as stem-final r-deletion (cf., (3)). He then sets up the relinking as depicted in (3a-b). Let us Consider the following representation of the r-deletion in the word /bakar/ 'burn':

(2)

r-Deletion in /bakar/ 'burn':

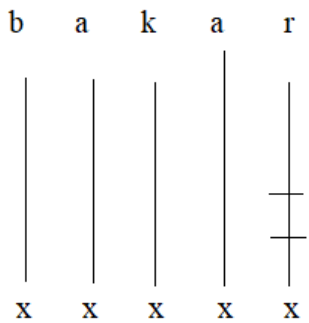

Based on the above representation, Teoh (1994:49) then accounted for the interactions between the r-Deletion, the vowel lengthening, and the vowel reduction affecting the underlying final stem vowel /a/ in /gula/ 'sugar' and /bakar/ 'burn', as shown below:

(3)

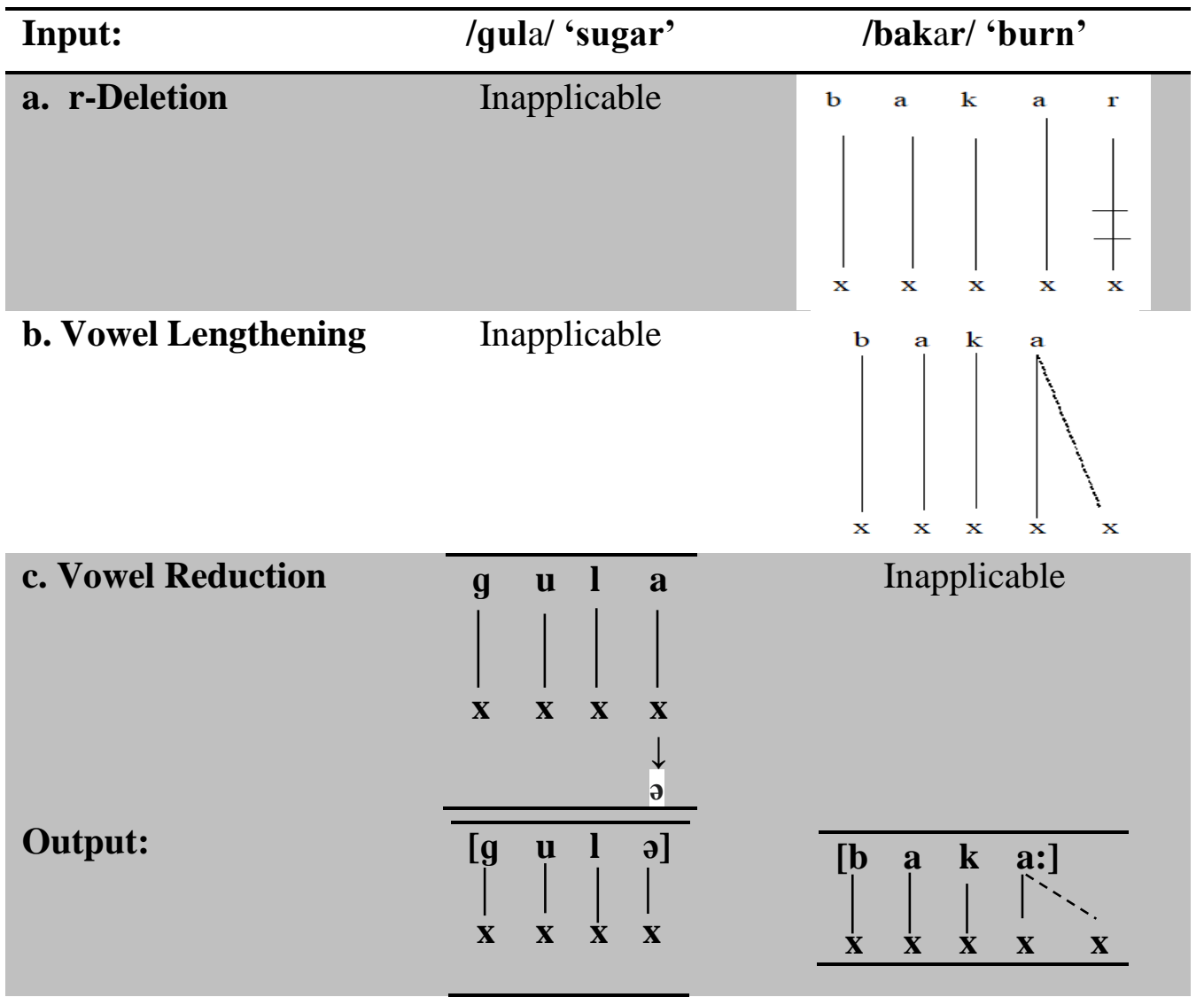

Taking steps (3a-b) into consideration, Teoh (1994) notes the fact that final /a/ in /bakar/ 'burn' is adjacent to the target of deletion, stem-final $/ \mathrm{r} /$. He concludes that the neighboring empty slot. preceding vowel, and yielded a vowel with two X-slots--a long vowel, immune to reduction.

Similarly, Kassin (2000) also believed that there was a relinking of the timing X-slot to the preceding vowel in Standard Malay, and claimed that for phonological word boundaries, the floating /r/ remained unlinked as it failed to resyllabify with the following V-initial words, 


\section{Theoretical Approach}

thereby becoming subject to CL. Therefore, Kassin (2000) inferred that the CL for the floating $/ \mathrm{r} /$ seen through deletion was as shown below:

(4) The CL rule for the floating /r/ (Kassin 2000: 97):

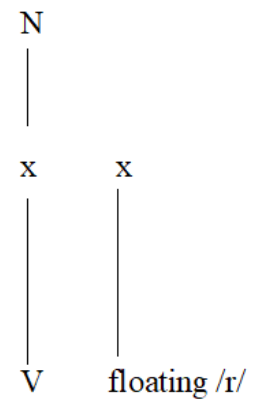

Kassin (2000) stated that the $\mathrm{x}$-tier of the delinked /r/ was attached to a rhyme after the deletion of the same segment, and as the floating / $/ \mathrm{r}$ strayed from a branching rhyme through the deletion, there was a compensatory vowel lengthening, as shown in (5) below:

(5) Delinking of the floating / $\mathrm{r} /$ and compensatory vowel lengthening (Kassin 2000: 98):

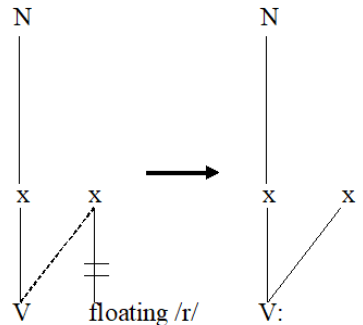

Although the above scholars addressed CL in Malay, the nature of the phonological derivation for this linguistic phenomenon has not yet been investigated using Stratal OT. Therefore, the aim of this research was to illuminate the phonological derivation behind CL in Standard Malay using Stratal OT, with a particular focus on the following two questions:

- What is the phonological derivation behind CL in Standard Malay?

- How can the phonological derivation in CL be accounted for using Stratal OT?

In order to address these two questions, let us first examine syllable structure in Standard Malay.

\section{STANDARD MALAY SYLLABLE STRUCTURE}

Standard Malay syllable structures have been analyzed by Abdullah (1974), Onn (1980), and Yunus (1980), all of whom argued that the basic syllable structure was (C)V(C). Standard Malay is typologically in the VI language group, which based on Clements \& Keyser's (1983) taxonomy of languages by core syllable type, includes four permitted syllable types: V, VC, $\mathrm{CV}$, and CVC. However, Teoh rejects this categorization, because of the obligatoriness of onsets in Malay, claiming instead that the language belongs to Group III languages, with $\mathrm{CV}(\mathrm{C})$ syllables, which require onsets. Zaharani $(2001,2005)$ supports the former classification, showing that onset satisfaction and violation argue for $(C) V(C)$ in Standard Malay: Onset satisfaction in Malay is achieved by avoidance of hiatus, such that $\mathrm{V}$-final prefixes attach to $\mathrm{V}$ initial stems accompanied by a glottal epenthesis intervocalically, as shown in the following examples: 
(6)

\begin{tabular}{clll}
\hline a. & /di+ubah/ & [di.' 'Pu.bah] & 'to move (passive)' \\
\hline b. & /dzuru+atfara/ & [dzu.ru.Pa. 't $\mathrm{da}$.ra] & 'master of ceremony' \\
c. & /sə+indah/ & [sə.' 'Pin.dah] & 'to be as beautiful as'
\end{tabular}

Another type of onset satisfaction in Standard Malay, as demonstrated by Zaharani (2001, 2005), is achieved by the resyllabification of the final consonant in the C-final prefix as an onset for the following syllable, as shown in the following examples: ${ }^{1}$

(7)

\begin{tabular}{|c|c|c|}
\hline a./məy+indah+kan/ & [mõ.yĩn. 'dah.kan] & 'to beautify' \\
\hline 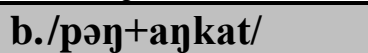 & [рә.' yãn.kat] & 'lifter (instrument)' \\
\hline c. /tər+elok/ & [tə.' re.lok] & 'most beautiful' \\
\hline d./bər+aykat/ & [bə.' rãn.kat] & 'to depart' \\
\hline
\end{tabular}

However, in his reference to ONS violations, Zaharani $(2001,2005)$ concurs with Onn (1980) and Yunus (1980), who confirm the existence in Standard Malay of onsetless initial syllables in bare roots, as seen in (8).

$(8)$

\begin{tabular}{|c|c|c|c|}
\hline a. & /ubah/ & ['u.bah] / *[' 'u.bah] & 'to change' \\
\hline b. & /indah/ & ['ĩn.dah]/ *['Pĩn.dah] & 'beautiful' \\
\hline c. & /elok/ & ['e.lo?]/ *['?e.lo?] & 'pretty' \\
\hline d. & /olah/ & ['o.lah]/ *[' Po.lah] & 'to beguile' \\
\hline e. & /aykat/ & ['ãy.kat]/ *['?ãy.kat] & 'to lift' \\
\hline f. & /əmak/ & [ə.' mā?]/ *[?ə.' mā?] & 'mother' \\
\hline
\end{tabular}

Another case of onset violation in Standard Malay, according to Zaharani (2001), can be found within the root domain, as in the following examples:

(9)

\begin{tabular}{|c|c|c|c|}
\hline a. & /kaen/ & ['ka.en]/*['ka.Pen] & 'cloth' \\
\hline b. & /naek/ & ['nã.ẽ?]/ *['nã.Pẽ?] & 'to ascend' \\
\hline c. & /maen/ & ['mã.ẽn]/ *['mã.?ẽn] & 'to play' \\
\hline d. & /haos/ & ['ha.os]/*['ha.?os] & 'thirsty' \\
\hline e. & /laot/ & ['la.ot $] / *$ ['la.Pot] & 'sea' \\
\hline
\end{tabular}

Even though a small class of consonants are prohibited in coda position in Standard Malay, ${ }^{2}$ single member codas, as optional constituents, are permitted (Teoh 1994; Zaharani 2004.). Teoh (1994) demonstrates that codas in Malay are restricted to segments specified [+anterior].

\footnotetext{
${ }^{1}$ Zaharani $(2001,2005)$ reports that the Principle of Minimal Onset Satisfaction (Roca 1994) motivates this type of syllabification.

2 Zaharani (2004) states that sounds of the [- anterior] feature are banned from coda position in Standard Malay.
} 
Those marked [-anterior] are disallowed, echoing the syllable Coda Condition (Itô 1986), as shown in the following constraint: ${ }^{3}$

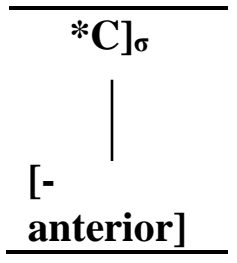

Teoh (1994) explained that the very few segments that occupy a specified [-anterior] coda position were loanwords (Yunus 1980: 69, Onn 1980: 13), such as the consonants $/ \mathrm{t} / \mathrm{f} / \mathrm{d} 3 /$, and /n/ in [mat5] 'march' and [ko.led3] (Yunus 1980: 69; Onn 1980: 13), and that the violation of the above constraint was not because of homorganic clusters such as [ndz] and [ntf],in words such as [pandzat] 'to climb' and [montfari] 'to find' because these clusters were partial geminates that have doubly-linked representations. However, Zaharani (2004) claimed that the syllable coda condition for Malay did not apply to doubly-linked structures because of Hayes's (1986) linking constraint. ${ }^{4}$

Zaharani (2004) observed another significant Malay syllable coda not captured in Teoh's (1994) syllable coda condition that had an impact on some consonant classes, such as the voiceless velar stop $/ \mathrm{k} /$, the voiced obstruents $/ \mathrm{b}, \mathrm{d}, \mathrm{g} /$, and the rhotic $/ \mathrm{r} /$, , and was peculiar to consonant deletion, debuccalization, and obstruent devoicing phonological processes. Commenting on the syllable coda condition, Zaharani (2004) pointed to the phonological behavior observations made by Blevins (1995: 228):

"Wherever possible, coda constraints should be supported by positive evidence from native and loan phonology in the form of stray Erasure, extraprosodicity, feature changing rules, or epenthesis triggered by arguably illicit coda segments. Only in such cases is there positive evidence of the systematic nature of gaps in the coda inventory."

Therefore, Zaharani (2004) proposed that the effect of the syllable coda condition and the apparent prohibition of $/ \mathrm{t} \int \mathrm{d} 3, \mathrm{n} /$ in coda was suspicious given the above supportive evidence, and that the absence of $/ \mathrm{t} \int \mathrm{d} 3, \mathrm{n} /$ in the native vocabulary was accidental. Zaharani's (2004) significant observation of the syllable coda in Malay was that the debuccalization, that is, the glottal formation, targets the voiceless velar stop / $/$, which occupies a coda to conform to the syllable coda condition. ${ }^{5}$ Consider the following examples:

\footnotetext{
${ }^{3}$ Zaharani (2004) stated that the above constraint introduced by Teoh (1994: 53) was not accurate as both $/ \mathrm{n} / \mathrm{and} / \mathrm{h} / \mathrm{can}$ occur in a coda position in Malay.

${ }^{4}$ Linking Constraint (Hayes 1986: 472): Association lines in structural descriptions are interpreted as exhaustive.

5 This process is found in other languages as documented by Lass (1976) and Hayes (1986); hence, Hayes (1986) claimed that a
} glottal stop in the coda position in Toba Batak is the result of the debuccalization of all voiceless stops in the same position. Lass (1976) reported a debuccalization of a voiceless alveolar stop /t/ to a glottal stop in the coda position in the English dialect of New York City and Scots dialects. 
(11)

\begin{tabular}{llll}
\hline a. & /saksi/ & ['sa?.si] & 'witness' \\
\hline b. & /laksa/ & ['la?.sa] & 'a kind of noodle' \\
c. & /sepak/ & ['se.pa?] & 'to kick' \\
d. & /kakak/ & ['ka.ka?] & 'sister' \\
e. & /kapak/ & ['ka.pa?] & 'an axe'
\end{tabular}

Although the native phonology of Malay permits both a voiced and voiceless obstruent, according to Zaharani (2004), the underlying voiced obstruents /b, d, g/ in loan phonology change into their voiceless counterparts $[\mathrm{p}, \mathrm{t}, \mathrm{?}]$ because of the syllable coda condition, as shown in the following examples:

\begin{tabular}{cccl}
\hline a. & /adab/ & ['a.dab] & 'manners' \\
\hline b. & /akad/ & ['a.kat] & 'decade' \\
c. & /ragbi// & ['ra?.bi] & 'rugby'
\end{tabular}

Another phenomenon related to the conformity to the syllable coda condition is peculiar to the r-deletion in the coda position, which results in vowel lengthening. ${ }^{6}$ This process is detailed in the next section. Consider the following examples:

\begin{tabular}{llll}
\hline a. & /kotor/ & ['ko.to:] & 'dirty' \\
\hline b. & /uker/ & ['u.ke:] & 'to crave' \\
c. & /ukor/ & ['u.ko:] & 'to measure' \\
d. & /pasar/ & ['pa.sa:] & 'market'
\end{tabular}

The earlier proposal regarding syllable structure in Standard Malay was supported by Kassin (2000), Gomez \& Reason (2002), Delilkan (2002), Zaharani (2005), Lee (2008), Fern \& Jiar (2013), and Masilamani (2019), all of whom agreed on the classification of Malay as a disyllabic language with four syllable structures: V, VC, CV, and CVC. Table 3 shows the basic Malay syllable structures with examples:

Table 1. Basic Standard Malay Syllable Structures (Kassin 2000; Gomez \& Reason 2002; Delilkan 2002; Zaharani 2005; Lee 2008; Fern \& Jiar 2013; Masilamani 2019)

\begin{tabular}{|c|c|c|c|}
\hline \multicolumn{2}{|c|}{ Syllable Structure } & Example & English Translation \\
\hline a. & V & ['i.bu] & 'mother' \\
\hline b. & $\mathbf{V C}$ & ['am.bil] & 'to receive'7 \\
\hline c. & CV & [kə.'nal] & 'know'8 \\
\hline d. & CVC & ['ban.tu] & 'assisting' \\
\hline
\end{tabular}

\footnotetext{
${ }^{6}$ The CVV syllable is derived from CVC syllables through the CL process.

7 The insertion of a glottal stop in the case of the word ambil 'to receive' is optional since the same word can be pronounced as ['Pam.bil] or ['am.bil] (El-Imam \& Don 2000).

${ }^{8}$ Stress in Malay primarily falls on the penultimate syllable unless the penultimate syllable has a schwa, when the stress shifts to the following syllable, i.e., ultimate syllable, according to Prentice (1987), Teoh (1994), and Delilkan (2002).
} 


\section{Theoretical Approach}

There are two basic Standard Malay syllable structures that need to be considered: the syllable division based on openness and closeness, and the moraic model syllable weight and syllabification. The basic syllable structures shown in Table 1 all fall into either open (V and $\mathrm{CV}$ ) or closed (VC and CVC) syllable categories, and for the second point, the syllabification of ['ban.tu] 'assisting' is illustrated below:

$$
\text { Syllabification of ['ban.tu] 'assisting' }
$$

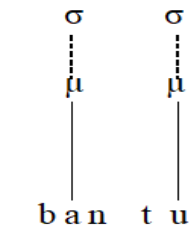

Association of a moraic segment to a syllable node
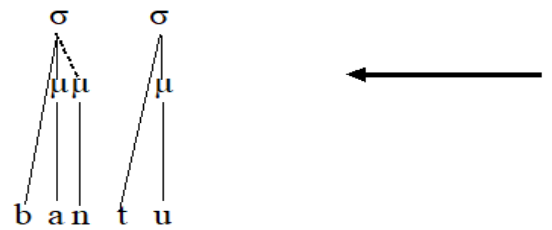

Adjunction of Weight-ByPosition mora to the syllable node
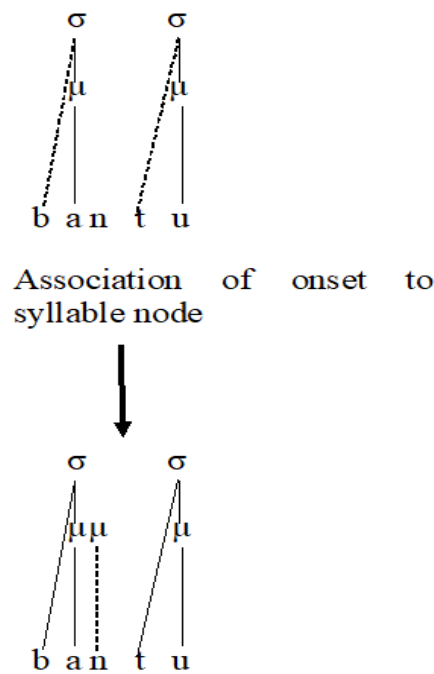

Assignment of mora through Weight-By-Position

As the syllabification and syllable weight of the words in (14) were identified using the moraic model, Zaharani (2005) and Zaharani \& Jalaluddin (2011) agreed that the underlyingly vowels were moraic and that the coda moracity was driven by the weight-by-position. Accordingly, in the syllabification of ['ban.tu] 'assisting', the vowels are deemed to be underlyingly moraic, which means that they are initially associated to the syllable nodes and that the moras are derivationally assigned codas because of the weight-by-position, after which they are adjoined to the syllable node. After demonstrating the syllable structure of Standard Malay, the next section specifically examines some Malay data.

\section{DATA COLLECTION AND ANALYSIS}

There were two main procedures followed in this research. First, the data were extracted from previous literature including books, articles, and theses and then several native Standard Malay speakers from Kuala Lumpur were consulted to verify the validity of the Standard Malay data.

As discussed, the CL in Standard Malay targets the / $\mathrm{r}$ / in the postvocalic position and is restricted to the stem-final $/ \mathrm{r} /$ preceding the short vowel within the same syllable, as shown in the following examples:

(15) CL in Standard Malay

\begin{tabular}{|c|c|c|c|}
\hline & Input & Output & English Translation \\
\hline I) & a. /uker/ & ['u.ke:] / *['u:.ke] & 'to crave' \\
\hline & b. /ukor/ & ['u.ko:] / *['ur.ko] & 'to measure' \\
\hline & c. /pasar/ & ['pa.sa:] / *['pa:.sa] & 'market' \\
\hline
\end{tabular}




\begin{tabular}{|c|c|c|c|}
\hline & d. /paser/ & ['pa.se:] / *['pa:.se] & 'sand' \\
\hline & e. /bakar/ & ['ba.ka:] / *['ba:ka] & 'burn' \\
\hline & f. /tukar/ & ['tu.ka:] / *['tu:.ka] & 'change' \\
\hline & g. /hindar/ & ['hin.da:] / *['hi:n.da] & 'avoid' \\
\hline & h. /samar/ & ['sa.ma:] / *['sa:.ma] & 'blur' \\
\hline & i. /kotor/ & ['ko.to:] / *['ko:.to] & 'dirty' \\
\hline & j. /tabor/ & ['ta.bo:] / *['ta:.bo] & 'spread' \\
\hline & k. /akar/ & ['a.ka:] / *['a:.ka] & 'root' \\
\hline & 1. /bənar/ & [bə.'na:] / *[bə:.'na] & 'true' \\
\hline & m. /sabar/ & [sa.'ba:]/*[sa:. 'ba] & 'patient' \\
\hline & n. /lebar/ & [le. 'ba:] / *[le:. 'ba] & 'wide' \\
\hline II) & a. /Par.nab/ & ['?a:. nab]/*['?a. na:b] & 'rabbit' \\
\hline III) & a. /uker+kan/ & [u.'ke:.kan] / *[u..'ke.kan] & 'crave (imperative)' \\
\hline & b. /pasar+kan/ & [pa.' sa:.kan] / *[pa:.'sa:.kan] & 'sell (imperative)' \\
\hline & c. tukar+kan/ & [tu.' ka:.kan] / *[tu.. 'ka.kan] & 'to change' \\
\hline & d. /tabor+kan/ & [ta.' bo:.kan] / *[ta:. 'bo.kan] & 'to spread' \\
\hline
\end{tabular}

In the above examples, the word-final /r/ in (15-I) and the root-internal /r/ in (15-II) are both vulnerable to CL. The examples in (15-III) demonstrate the CL application to the root-final $/ \mathrm{r} /$ in their attachment to the consonant-initial suffix. However, is the deletion of the $/ \mathrm{r} /$ in the coda obligatory or optional? In the previous rule-based analysis, Onn (1980: 16) claimed that the [r] in the stem-final position was absent because of an obligatory $/ \mathrm{r} /$ deletion rule, which was in agreement with previous analyses by Asmah (1975) and Yunus (1980). Consider the following /r/ deletion rule:

(16) $\quad / r /$ deletion rule (Onn 1980: 16)

$$
\mathrm{r} \rightarrow \varnothing /[\{\#, \mathrm{C}\}
$$

However, Teoh (1994) posited that the [r] in the stem-final position was optionally deleted due to the /r/ delinking rule, as shown below:

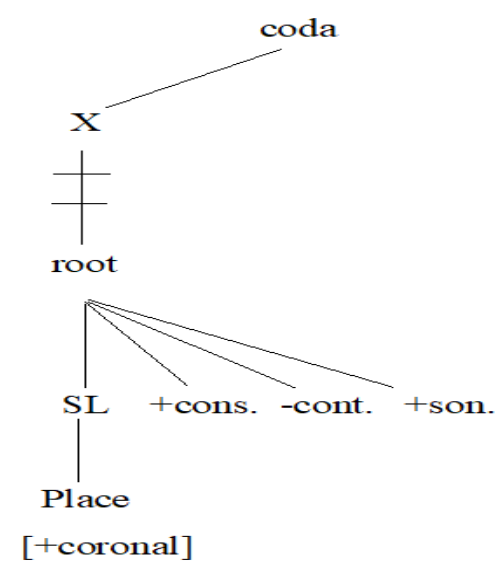

However, in agreement with Asmah (1975), Yunus (1980), and Onn (1980), Zaharani (2004) disagreed with Teoh (1994), stating that the /r/ deletion was obligatory based on 


\section{Theoretical Approach}

contemporary data, was motivated by the syllable coda condition, as explained in the previous section, and was followed a vowel lengthening, that is, CL. Therefore, to explore this further, a metrical analysis of CL in Standard Malay is offered in the subsequent subsection.

\subsection{Metrical Analysis of Cl in Standard Malay}

Hayes (1989) claimed that the metrical approach to CL was derivational as it encompassed two steps: the deletion of a consonant associated with the mora, which results in a floating, unassociated mora without any segment, and the linking of this floating mora with the preceding vowel, at which time vowel lengthening takes place, as shown in the following schematic:

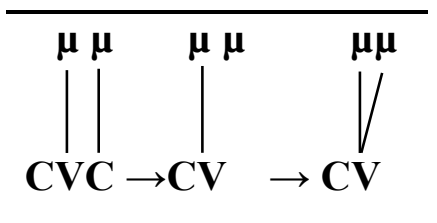

Therefore, in Standard Malay, the CL is a twofold process targeting the stem-final /r/: the deletion of the stem-final $/ \mathrm{r} /$ associated with the mora to yield the floating mora, and the linking of the floating mora with the preceding vowel, resulting in the vowel lengthening. This CL is autosegmentally illustrated in the representation below for the /u.ker+kan/ 'crave (imperative)'output (Note that ' $F$ ' $=$ foot and 'PrWd'= Prosodic Word).

$$
\text { /u.ker.kan/ } \rightarrow \text { [u.' ke:.kan] 'crave (imperative)' }
$$
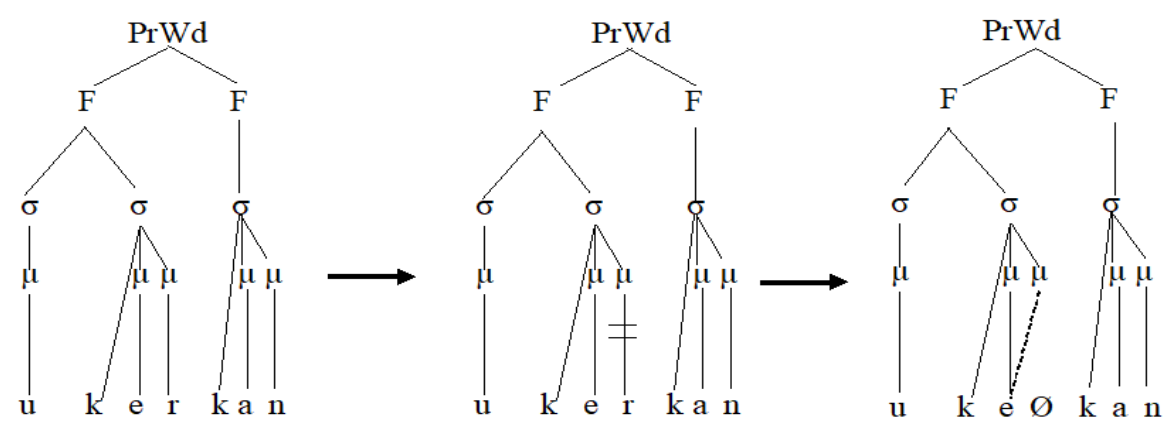

On the other hand, the crossing of the association lines is caused by long-distance CL in the wrong outputs in (15), resulting in irredeemably ill-formed syllables, as seen in the following representation:

$$
\text { /u.ker.kan/ } \rightarrow *[\mathbf{u} . \text { ke.kan] 'crave (imperative)' }
$$



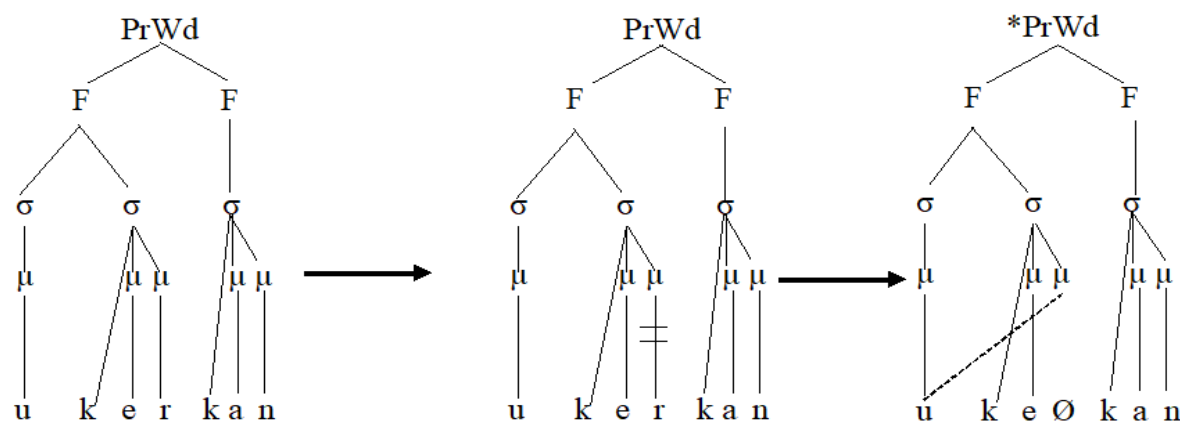

CL in Standard Malay is an opaque rule interaction that involves the over application of WBP, that is, the assignment of a mora to the stem-final / $\mathrm{r} /$ prior to its deletion. This type of phonological opacity is known as counterbleeding, where the deletion of the stem-final $/ \mathrm{r} /$ counterbleeds the WBP, as shown in (21).

Counterbleeding order in Standard Malay:

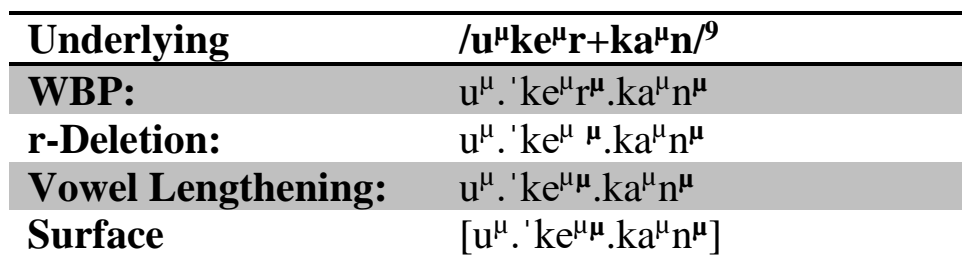

To demonstrate how Stratal OT is capable of accounting for any opaque rule interaction, before the Stratal OT analysis of the counterbleeding order in (21), it is necessary to examine how this type of phonological opacity is addressed by OT models. Therefore, the next subsection offers an analysis of the derivational OT versions.

\subsection{Derivational Versions of $\mathrm{OT}$}

Dealing with phonological opacity such as counterbleeding is somewhat complicated (Idsardi 1997, 2000; Kager 1999; McCarthy 1999; Kiparsky 2000, 2003). For example, McCarthy (1999: 2) claimed that "as OT is currently understood, though, constraint ranking and violation cannot explain all instances of opacity. Unless further refinements are introduced, OT cannot contend successfully with any non-surface-apparent generalizations nor with a residue of nonsurface-true generalizations." Therefore, with reference to counterbleeding in Tiberian Hebrew, according to McCarthy (1999) and Kiparsky (2000, 2003), correspondence theory, which is an output-output faithfulness model, is unsuitable for dealing with counterbleeding as this model does not provide a complete solution to the opacity problem.

McCarthy (1999) claimed that sympathy theory as an OT model could be an ad hoc solution to the opacity problem; however, the use of this model was criticized by Idsardi (1997, 2000), Kiparsky (2000), and Itô \& Mester (2003). Kiparsky (2000) presented a strong argument against the capability of this model to handle the opaque interactions of stress and vowel in Palestinian Arabic by demonstrating that the need for different sympathy constraints (referring

\footnotetext{
${ }^{9}$ The assumption that the vowels are underlyingly moraic does not dispute the richness of the base hypothesis (Prince \& Smolensky 1993) that vowels are universally and underlyingly moraic. On the other hand, Sprouse (1997) claimed that moras that trigger vowel lengthening are not part of the input.
} 
to the same selector) for each different opaque process caused chaos in the Palestinian Arabic system.

The introduction by McCarthy (2007) of an inherently derivational variant of the classic OT called harmonic serialism was another attempt to account for the opacity. This model (McCarthy 2007; Samko 2011) involves the input making multiple passes through the same constraint ranking, with the winning candidate in each pass being employed as the input to the following stage until the faithful candidate concomitant with the coverage of the derivation is determined. However, McCarthy (2007: 37) found that 'wherever classic OT has a problem with counterbleeding opacity, harmonic serialism will too, since harmonic serialism is just classic OT, iterated'. Unlike McCarthy (2007), Samko's (2011) work on CL in harmonic serialism revealed that when this model was aligned with the fully faithful candidate plus candidate chains (OT-CC) (McCarthy 2007) model, it was able to handle the counterbleeding as an opaque rule interaction. Although Samko's (2011) findings showed that the counterbleeding could be handled with harmonic serialism, whether it was able to deal with counterfeeding was not investigated. Therefore, as this model's ability to account for opaque processes is limited, as shown in McCarthy (2007) and Elfner (2016), it is concluded that harmonic serialism is unable to account for counterfeeding opacity. ${ }^{10}$ The next subsubsection is devoted to demonstrate how Stratal OT can successfully account for CL in Standard Malay as an opaque rule interaction.

\subsubsection{Stratal OT}

As Stratal OT as an OT model can account for both counterbleeding and counterfeeding, it is utilized to account for the counterbleeding in the current study (Kiparsky 1997a, 1997b, 2000, 2003; Bermúdez-Otero 1999, 2008; McCarthy 1999; Staroverov 2014). Simply put, this model can account for the otherwise opaque rules. The difference between standard OT, where the input is directly mapped onto the output, and the stratal approach, where the stages between the input and output have different sets of OT constraints, was discussed in Kager (1999: 381385). The representation in (22) shows how Stratal OT works.

(22) Stratal OT (Kager 1999: 382)

Input

${ }^{10}$ Hauser and Haughto (2018) invoke the contextual faithfulness constraints to account for both counterfeeding and counterbleeding using Harmonic Serialism. Although these constraints successfully help Harmonic Serialism to account for the phonological opacity, i.e. counterbleeding and counterfeeding, behind the segmental changes such as palatalization, devoicing, and spirantization, as well as segment deletion, Hauser and Haughto (2018) do not mention whether these constraints can account for the moracity assignment prior to segment deletion and vowel lengthening as seen in compensatory lengthening or not. This success is obviously limited to a certain extent and cannot be expanded to address building the prosodic structure before the occurrence of any phonological processes. 
Stratum 1 Gen Eval $_{1}$

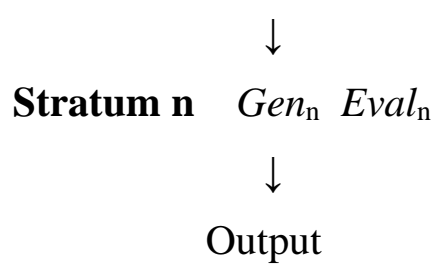

Based on the representation above, the output in Stratum 1 serves as the input for the following Stratum n. To account for the counterbleeding stemming from the CL in Standard Malay using Stratal OT, it is vital to ensure that the moraic structure is built prior to the segmental changes, that is, the moracity assignment to the stem-final $/ r /$ must be the step before the $r$-deletion. Accordingly, the first step at the stem level (Stratum 1) is focused on building the moraic structure before the consonant deletion. The optimal output in this step is then employed as the input for the following step at the word level (Stratum 2) when the derivation is over. As these strata are established with reference to Malay morphology, before analyzing this process, consider the relevant OT constraints in (23):

(23) Relevant constraints:

a. WBP (Hayes 1989)

Assign a violation for each coda consonant that is not moraic.

b. MAX $[\mu]$ (McCarthy 1997)

Assign a violation for each mora in the input that is not present in the output.

c. WFC (b) (Byrd and Sandell 2015)

Association lines do not cross. Assign one violation for each crossed association line.

d. MAX (McCarthy \& Prince 1995)

Assign a violation for each segment in the input that is not present in the output.

e. *FINAL-RHOTICS

Word-final rhotics are prohibited.

f. DEP (McCarthy \& Prince 1995):

Every segment of $S_{2}$ has a correspondent in $S_{1}\left(S_{2}\right.$ is "dependent on" $\left.S_{1}\right)$.

g. DEP $[\mu]$ (McCarthy 1997)

Assign a violation for each mora in the output that is not present in the input.

h. *FLOAT (Samko 2011: 29)

Assign a violation for each mora in the output that is not associated with a segment.

Therefore, with regard to the above constraints, the following tableaux account for the counterbleeding order for the input $/ \mathrm{u}^{\mu} \mathrm{ke}^{\mu} \mathrm{r}+\mathrm{ka}^{\mu} \mathrm{n} /$ 'crave (imperative)':

Tableau 2:

Stratum (1) (Stem level):

WBP $>>$ MAX $>>$ DEP $>>*$ FINAL-RHOTICS $>>*$ FLOAT $>>$ WFC $(b)>>M A X[\mu]>>$ DEP $[\mu]$ 


\begin{tabular}{|c|c|c|c|c|c|c|c|c|}
\hline$/ \mathbf{u}^{\mu} \mathbf{k} \mathbf{e}^{\mu} \mathbf{r}+\mathbf{k} \mathbf{a}^{\mu} \mathbf{n} /$ & $\frac{1}{2}$ & $\sum$ & 牙 & $\frac{3}{2}$ & $\underset{*}{\sigma}$ & $\underset{b}{2}$ & $\frac{\Xi}{\bar{z}}$ & $\frac{3}{2}$ \\
\hline a. $u^{\mu} \cdot k^{\mu}{ }^{\mu} \cdot k a^{\mu} n$ & $* ! *$ & & & $*$ & & & & \\
\hline b. $u^{\mu} \cdot k e^{\mu} r^{\mu} \cdot k a^{\mu} n^{\mu}$ & & & & $*$ & & & & $* *$ \\
\hline c. $u^{\mu} \cdot k e^{\mu} \cdot r \partial^{\mu} \cdot k a^{\mu} n^{\mu}$ & & & $* !$ & & & & & $* *$ \\
\hline d. $\mathbf{u}^{\mu} \cdot \mathbf{k e}^{\mu} \cdot \mathbf{k a}^{\mu} \mathbf{n}^{\mu}$ & & $* !$ & & & & & & $*$ \\
\hline
\end{tabular}

Whereas candidate (a) in Stratum (1) fatally violates the WBP constraint, the remainder of the candidates satisfy the same constraint. While candidate (c) permits vowel epenthesis and conforms to the *FINAL-RHOTICS, it fails to be optimal because of the DEP violation. Candidate (d) allows the r-deletion as a segmental process to avoid the violation of *FINALRHOTICS, but the DEP is eliminated, which is a violation of MAX. Consequently, candidate (b) is the optimal desired output and is employed as the input in Tableau 3 (i.e., Stratum (2)).

Tableau 3:

Stratum (2) (Word level):

WBP $>>*$ FINAL-RHOTICS $>>$ DEP $>>$ MAX $[\mu]>>*$ FLOAT $>>$ WFC $(b)>>$ MAX $>>$ DEP $[\mu]$

\begin{tabular}{|c|c|c|c|c|c|c|c|c|}
\hline$/ \mathbf{u}^{\mu} \cdot \mathbf{k e}^{\mu} \mathbf{r}^{\mu} \cdot \mathbf{k} \mathbf{a}^{\mu} \mathbf{n}^{\mu} /$ & $\frac{1}{3}$ & 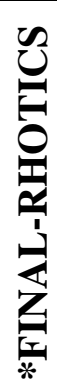 & $\frac{a}{a}$ & $\frac{3}{z}$ & $\underset{*}{\sigma}$ & $\underbrace{0}_{0}$ & $\Sigma$ & $\frac{\Xi}{2}$ \\
\hline$a \cdot u^{\mu} \cdot k e^{\mu} r^{\mu} \cdot k a^{\mu} n^{\mu}$ & & $* !$ & & & & & & \\
\hline b.u $\mathbf{u}^{\mu} \cdot \mathbf{k} \mathbf{e}^{\mu} \cdot \mathbf{k} \mathbf{a}^{\mu} \mathbf{n}^{\mu}$ & & & & $* !$ & & & * & \\
\hline c. $\mathbf{u}^{\mu} \cdot k \mathrm{e}^{\mu \mu} \cdot \mathrm{ka}^{\mu} \mathbf{n}^{\mu}$ & & & & & *! & & $*$ & \\
\hline d. $u^{\mu} \cdot k e^{\mu \mu} \cdot k a^{\mu} n^{\mu}$ & & & & & & & * & \\
\hline e. $u^{\mu \mu} \cdot k e^{\mu} \cdot k a^{\mu} n^{\mu}$ & & & & & & $* !$ & * & \\
\hline
\end{tabular}

The *FINAL-RHOTICS is fatally violated by candidate (a), which is initially eliminated, and while a *FINAL-RHOTICS violation is avoided by candidate (b), the MAX $[\mu]$ is violated, and the floating mora in candidate (c) violates *FLOAT. Candidate (e), as the most challenging output, avoids the violation of *FLOAT through long-distance CL which results in the crossing of the association line, incurring the fatal violation of the WFC (b) constraint. Therefore, compared to the other candidates, candidate (d) with the lengthened vowel is determined as optimal because the phonological derivation or counterbleeding in Stratum (2) avoids any violation of *FINAL-RHOTICS, MAX $\mu \mu]$, and *FLOAT. 
To summarize, when seeking to reference CL in Standard Malay, because the strata in the Stratal OT model are established based on Malay morphology, the model is superior to previous analyses and can account for the phonological opacity of counterbleeding. The moraic structure built in Stratum 1 is accomplished before CL takes place in Stratum 2, in which the phonological derivation is covered.

\section{CONCLUSION}

This study examined the phonological derivation of CL in Standard Malay using a Stratal OT model. CL in Standard Malay is common for the stem-final /r/, which becomes moraic due to WBP. To put it simply, the CL precedes the moracity assignment to the stem-final $/ \mathrm{r} /$ to ensure the moraic structure is built prior to the deletion and lengthening. The deletion of the moraic stem-final /r/ results in a floating mora, which is then linked to the preceding stem vowel and lengthened. This phonological derivation is an example of counterbleeding, that is, the CL counterbleeds WBP. This type of phonological derivation was accounted for using Stratal OT, which was proven to be superior to other analyses when seeking to account for opacity because the strata were developed based on Malay morphology. These strata were demonstrated under different OT constraints in each step. For instance, Stratum (1) confirmed the building of the the moraic structure prior to the CL, which occurs in Stratum (2) (i.e. at the end of the phonological derivation).

\section{ACKNOWLEDGMENT}

The researcher is very grateful to the Research Center in the Faculty of Languages and Translation and Deanship of Scientific Research at King Saud University for funding this research.

\section{REFERENCES}

Asmah, H. O. (1975). Essays on Malaysian Linguistics. Kuala Lumpur: Dewan Bahasa dan Pustaka.

Bermúdez-Otero, R. (1999). Opacity: evidence from West Germanic Gemination. In Spring Meeting of the Linguistics Association of Great Britain, Manchester.

http://citeseerx.ist.psu.edu/viewdoc/download?doi=10.1.1.544.3047\&rep=rep1\&type=pdf

Bermúdez-Otero, R. (2008). Stratal Optimality Theory . Oxford: Oxford University Press.

Blevins, J. (1995). The syllable in phonological theory. In Goldsmith, John A. (ed.), The Handbook of Phonological Theory. Oxford: Basil Blackwell.

Clements, G., \& Keyser, S. J. (1983). CV Phonology: A Generative theory of the syllable. Cambridge MA: MIT Press.

Collins, J., \& Hassan, N. (1986). Dialek Melayu Selangor: Tinjauan di Jugra. Jurnal Persatuan Linguistik 2. 74-94.

Delilkan, A. (2002). Stress Placement in Complex Words in Malay. New York: New York University, New York. TLS VII: 2002 Proceedings.

Elfner, E. (2016). Stress-epenthesis interactions in Harmonic Serialism. In McCarthy, John \& Pater, Joe (eds.), Harmonic Grammar and Harmonic Serialism, 261-300. London:

Equinox Publishing. 
El-Imam, Y., \& Don, Z. (2000). Text-to-speech conversion of standard Malay. International Journal of Speech Technology 3(2). 129-146.

https://link.springer.com/content/pdf/10.1023/A:1009693330163.pdf

Fern, N. P., \& Jiar, Y. K. (2013). Lexical properties and early literacy acquisition of kindergarten children in Malay orthography. Journal of Education and Practice, 4(12), 139-151.

http://citeseerx.ist.psu.edu/viewdoc/download?doi=10.1.1.1029.9893\&rep=rep1\&type=pdf

Gomez, C., \& Reason, R. (2002). Cross-linguistic transfer of phonological skills: a Malaysian perspective. Dyslexia, 8(1), 22-33.

https://onlinelibrary.wiley.com/doi/pdf/10.1002/dys.195?casa_token=CVy3fwOsI8AAAAAA :rqHrcM1z-vlmnLFkUqfSy04g1z8qpfao20z50ZNkuOENqdmNDqar69xgN8RSXj0nbpfJHafk0RLToE

Hassan, A. (1974). The morphology of Malay. Kuala Lumpur: Dewan Bahasa dan Pustaka.

Hauser, I., \& Hughto, C. (2018). Faithfulness-based opacity in Harmonic Serialism. Ms., University of Massachusetts, Amherst.

https://blogs.umass.edu/ihauser/files/2013/09/opacityHS-hauser-hughto.pdf

Hayes, B. (1986). Assimilation as spreading in Toba Batak. Linguistic Inquiry 17(3). 467499.

https://www.jstor.org/stable/4178500?seq=1

Hayes, B. (1989). Compensatory lengthening in moraic phonology. Linguistic Inquiry 20(2). 253-306.

https://citeseerx.ist.psu.edu/viewdoc/download?doi=10.1.1.451.5442\&rep=rep1\&type=pdf

Idsardi, W. J. (1997). Sympathy creates chaos. Ms., University of Delaware.

Idsardi, W. J. (2000). Clarifying opacity. Linguistic Review 17(2/4). 337-350.

https://www.degruyter.com/document/doi/10.1515/tlir.2000.17.2-4.337/html

Itô, J. (1986). Syllable Theory in Prosodic Phonology. PhD dissertation. University of Massachusetts, Amherst.

Itô, J., \& Mester, A. (2003). On the sources of opacity in OT: Coda processes in German. In Féry, Caroline \& van de Vijver, Ruben (eds.), The syllable in optimality theory, 271-303. Cambridge: Cambridge University Press.

Kager, R. (1999). Optimality Theory. Cambridge: Cambridge University Press.

Kassin, T. A. (2000). The phonological word in Standard Malay. PhD thesis. Newcastle University.

Kiparsky, P. (1997a). Remarks on denominal verbs. Complex Predicates 64. 473-499. http://www.fosssil.in/kiparsky\%201997\%20denominal\%20verbs.pdf

Kiparsky, P. (1997b). The rise of positional licensing. In van Kemenade, Ans \& Vincent, Nigel (eds.), Parameters of morphosyntactic change, 460-494. Cambridge: Cambridge University Press.

https://citeseerx.ist.psu.edu/viewdoc/download?doi=10.1.1.205.9829\&rep=rep1\&type=pdf 
Kiparsky, P. (2000). Opacity and cyclicity. Linguistic Review 17(2-4). 351-366.

http://citeseerx.ist.psu.edu/viewdoc/download?doi=10.1.1.206.1469\&rep=rep1\&type=pdf

Kiparsky, P. (2003). Syllables and moras in Arabic. In Féry, Caroline \& van de Vijver, Ruben (eds.), The syllable in optimality theory, 147-182. Cambridge: Cambridge University Press.

http://www.ai.mit.edu/projects/dm/featgeom/kiparsky03-arabicsyll.pdf

Lass, R. (1976). English Phonology and Phonological Theory. Cambridge: Cambridge University Press.

Lee, L. W. (2008). Development and validation of a reading-related assessment battery in Malay for the purpose of dyslexia assessment. Annals of Dyslexia 58. 37-57. https://link.springer.com/content/pdf/10.1007/s11881-007-0011-0.pdf

Masilamani, M. B. (2019). Influence of morphological, orthographic and phonological awareness in writing skills among bilingual Malay-English speakers: a study of adult (preuniversity) students in Peninsular Malaysia. PhD thesis. University of Canterbury.

McCarthy, J. (1997). Process-specific constraints in Optimality Theory. Linguistic Inquiry 28(2). 231-251.

https://scholarworks.umass.edu/cgi/viewcontent.cgi?article $=1060 \&$ context=linguist_faculty pubs

McCarthy, J. (1999). Sympathy and phonological opacity. Phonology 16(3). 331-399. https://scholarworks.umass.edu/cgi/viewcontent.cgi? article=1077\&context=linguist faculty_p $\underline{\mathrm{ubs}}$

McCarthy, J. (2007). Hidden generalizations: Phonological opacity in Optimality Theory. London: Equinox.

McCarthy, J., \& Prince, A. (1995). Faithfulness and reduplicative identity. In Beckman, Jill, Dickey, Laura Walsh \& Urbanczyk, Suzanne (eds.), Papers in Optimality Theory 18, 249384. Amherst: Graduate Linguistics Student Association.

https://scholarship.libraries.rutgers.edu/discovery/delivery?vid=01RUT_INST:ResearchRepo sitory\&repId=12643455900004646\#13643527590004646

Onn, F. (1980). Aspects of Malay phonology and morphology: A Generative approach. Bangi: Universiti Kebangsaan Malaysia.

Prentice, D. (1987). Malay (Indonesian and Malaysian). In Comrie, Bernard (ed.), The world's major languages, 913-935. New York: Oxford University Press.

Prince, A., \& Smolensky, P. (1993). Optimality Theory: Constraint interaction in generative grammar. New Jersey: Blackwell Publishing.

Roca, I. (1994). Generative Phonology. London: Routledge.

Samko, B. (2011). Compensatory lengthening in harmonic serialism. Santa Cruz: University of California, Santa Cruz. (Qualifying paper.)

https://citeseerx.ist.psu.edu/viewdoc/download?doi=10.1.1.387.4176\&rep=rep1\&type=pdf

Sandell, R., \& Byrd, A. M. (2015). Extrametricality and Non-Local Compensatory Lengthening: The Case of Szemerényi's Law. In LSA Annual Meeting, Portland, Oregon.

Sprouse, R. (1997). A case for enriched inputs. Handout of a presentation at TREND, 3. 
Staroverov, P. (2014). Opacity in Lardil: Stratal vs. serial derivations in OT. In Assmann, Anke, Bank, Sebastian, Georgi, Doreen, Klein, Timo, Weisser, Philipp \& Zimmermann, Eva (eds.), Topics at InfL: Linguistische Arbeitsberichte 92, 33-64. Leipzig: University of Leipzig.

https://www.philol.uni-

leipzig.de/fileadmin/Fakult\%C3\%A4t_Philo/Linguistik/Forschung/LAB/LAB_92/LAB92_02 staroverov.pdf

Teoh, B. S. (1994). The sound system of Malay revisited. Kuala Lumpur: Dewan Bahasa dan Pustaka.

Yunus, M. (1980). The Malay sound system. Kuala Lumpur: Fajar Bakti.

Zaharani, A. (1991). The phonology and morphology of the Perak Dialect. Kuala Lumpur: Dewan Bahasa dan Pustaka.

Zaharani, A. (2001). Onset satisfaction and violation in Malay: An optimilaty account. In Thurgood, Graham W (ed.), Papers from the Ninth Annual Meeting of the Southeast Asian Linguistics Society, 135-160. Tempe: Arizona State University, Program for Southeast Asian Studies.

http://sealang.net/sala/archives/pdf4/ahmad1999onset.pdf

Zaharani, A. (2004). Alignment and the syllable coda condition in Malay: An optimality account. GEMA Online ${ }^{\circledR}$ Journal of Language Studies 4(2).

https://ejournal.ukm.my/gema/article/viewFile/201/174

Zaharani, A. (2005). Phonology-morphology interface in Malay: An Optimality Theoretic account. Pacific Linguistic: Australia National University.

Zaharani, A., \& Jalaluddin, N. H. (2011). The phonology of words with monosyllabic stems in Malay. e-BANGI 6(1). 14.

https://ejournals.ukm.my/ebangi/article/view/21871/6748

\section{AUTHOR'S BIO}

Mufleh Salem M. Alqahtani, Ph.D., is an associate professor in Theoretical Linguistics (Phonology) at King Saud University. He has obtained his MA in Applied Linguistics from the University of Sussex in the UK and his Ph.D. in Linguistics from the University of Newcastle Upon Tyne in the UK. He has published articles peculiar to some phenomena in Somali and Persian languages. He is a member of one of the researched groups endorsed by the Deanship of Scientific Research at King Saud University. https://orcid.org/0000-0003-2546$\underline{4584}$ 